\title{
A Novel Hybrid Stent with Endoscopic Vacuum Therapy for Treating Leaks of the Upper Gastrointestinal Tract
}

\author{
Seung-Hun Chon ${ }^{a} \quad$ Ulrich Töx $^{\mathrm{b}} \quad$ Florian Lorenz $^{\mathrm{b}} \quad$ Isabel Rieck $^{\mathrm{b}}$ \\ Britta Janina Wagner ${ }^{c}$ Robert Kleinert ${ }^{a}$ Hans Friedrich Fuchs ${ }^{a}$ \\ Tobias Goeser $^{b} \quad$ Alexander Quaas ${ }^{c} \quad$ Christiane J. Bruns ${ }^{a}$ \\ aDepartment of General, Visceral, Cancer, and Transplant Surgery, University Hospital Cologne, Cologne, Germany; \\ ${ }^{b}$ Department of Gastroenterology and Hepatology, University Hospital Cologne, Cologne, Germany; ${ }^{\mathrm{C} D e p a r t m e n t}$ \\ of Pathology, University Hospital Cologne, Cologne, Germany
}

\section{Keywords}

Endoscopic vacuum therapy · Self-expanding metal stent Anastomotic leak · Esophageal perforation

\begin{abstract}
Introduction: Self-expanding metal stents (SEMS) are an established option for treating leaks in the upper gastrointestinal tract, and endoscopic vacuum therapy (EVT) has become a promising alternative. A novel approach is the use of an esophageal hybrid SEMS (VACStent $\left.{ }^{\circledR}\right)$, which can maintain esophageal passage during EVT. We present the first study demonstrating successful use of the VACStent ${ }^{\circledR}$ for treating leaks of the upper gastrointestinal tract. Method: We performed a retrospective, single-center study of all patients who underwent endoscopic stenting with the VACStent ${ }^{\circledR}$ of leaks in the upper gastrointestinal tract. Results: Indications for treatment with the VACStent ${ }^{\circledR}$ were: iatrogenic esophageal perforation $(n=1)$, spontaneous perforation $(n=2)$, esophageal fistula $(n=2)$, and anastomotic leak after upper gastrointestinal surgery $(n=5)$. Successful application of the VACStent ${ }^{\circledR}$ was achieved in all patients $(n=10 ; 100 \%)$ with a total of 15 interventions. VACStent ${ }^{\circledR}$ therapy was used as a first-line treatment in 5 patient (success rate $80 \%$; 4 out 5 patients) and as a second-line treatment after failed previous endoscopic therapy in 5 patients (success rate $60 \% ; 3$ out of 5 patients). Overall, VACStent ${ }^{\circledR}$ treatment was successful in $70 \%$ of the patients (7 out of 10). No severe VACStent ${ }^{\circledR}$ treat-
\end{abstract}

ment-related adverse events occurred. Conclusion: The initial experience has been that the technical application of the VACStent ${ }^{\circledR}$ is safe and technically feasible. However, due to the small number of patients this study could not show the clear advantages of this novel hybrid stent. More studies are necessary to show significant advantages.

(c) 2020 S. Karger AG, Basel

\section{Introduction}

Benign esophageal perforations and leaks following upper gastrointestinal surgery and endoscopy are severe adverse events $[1,2]$. Various therapeutic strategies, ranging from surgical repair to a variety of endoscopic interventional techniques, have been developed [3, 4]. Selfexpanding metal stents (SEMS) represent an established therapeutic option, and endoscopic vacuum therapy (EVT) has become a promising alternative [5-7]. Currently, there is no conclusive evidence to suggest the superiority of either of these methods $[8,9]$.

An innovative approach to the treatment of esophageal leaks is the combination of SEMS with EVT $[10,11]$. This method is aimed at optimizing the suction power by using the stent to create a seal between the sponge and the esophageal mucosa.

Since 2019, a fully covered esophageal hybrid SEMS (VACStent ${ }^{\circledR}$; Möller Medical GmbH, Germany) is avail- 


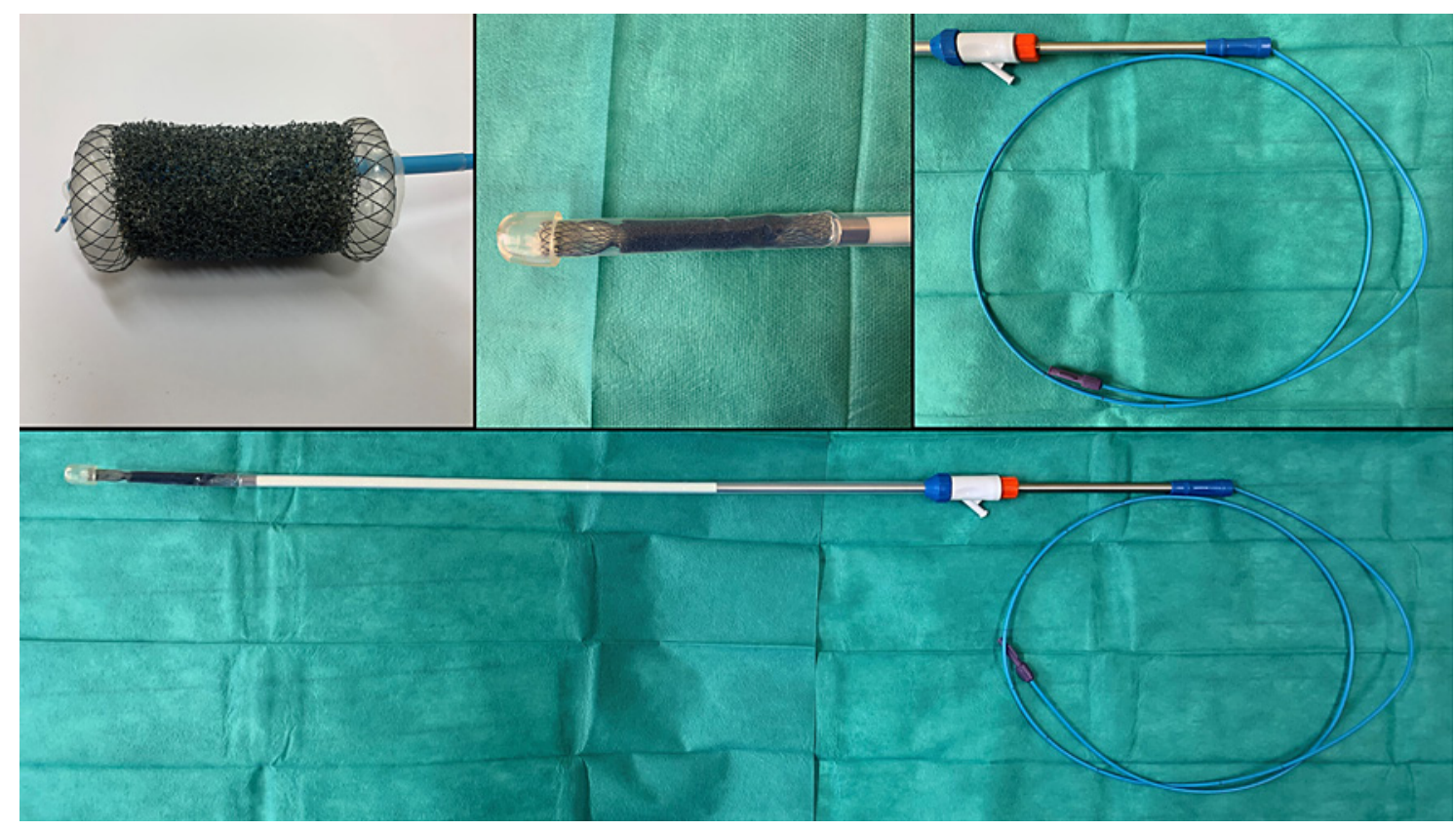

Fig. 1. The VACStent ${ }^{\circledR}$. a Fully covered SEMS (dimensions: $30 \times 14 \times 72 \mathrm{~mm}$ ) coated with polyurethane foam and connected to a blue suction tube. b VACStent ${ }^{\circledR}$ inside the delivery system. $\mathbf{c}$ End of the delivery system with the blue suction tube. $\mathbf{d}$ Complete delivery system.

Fig. 2. VACStent ${ }^{\circledR}$ treatment.

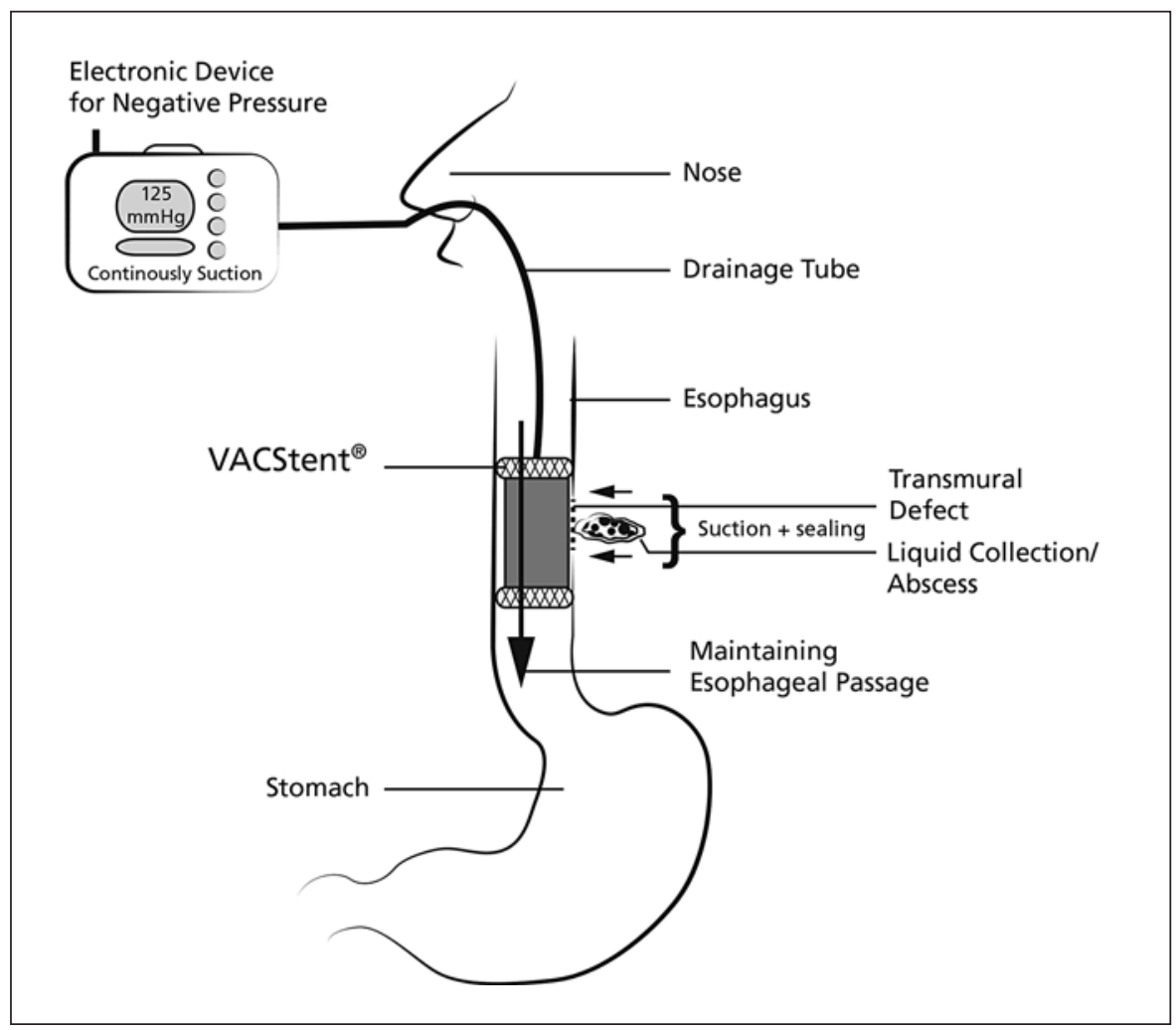

able on the German market [12]. It was designed to combine the advantages of both methods in 1 device, i.e., sealing the leak and maintaining esophageal passage for oral intake (SEMS) while supporting effective drainage (EVT).
So far, there is no existing data regarding the safety and efficacy of VACStent ${ }^{\circledR}$ treatment for leaks in the upper gastrointestinal tract. This paper reports our initial experience with the VACStent ${ }^{\circledR}$ in 10 consecutive patients. 


\section{Materials and Methods}

This study was performed at the Department of General, Visceral, Cancer, and Transplant Surgery at the University Hospital Cologne, which is a national referral center for surgery of the upper gastrointestinal tract. The VACStent ${ }^{\circledR}$ was used in 10 consecutive patients who were treated at our hospital between May and September of 2019 after endoscopic diagnosis of an esophageal leak. Data was collected from our prospectively managed endoscopic database Clinic WinData (version 8.08; E\&L Medical Systems $\mathrm{GmbH}$, Erlangen, Germany) and our hospital database Orbis (version 08043301; Agfa HealthCare N.V., Belgium).

\section{Patient Selection for the VACStent ${ }^{\circledR}$}

In our institute, with more than 200 upper gastrointestinal malignancy cases each year, the standard endoscopic treatment approach for upper gastrointestinal leaks is either fully covered SEMS treatment or EVT [6, 7]. If a leak presents with a septic condition of the patient, immediate ICU treatment and specific antisepsis treatment are administered, including drainage of fluid collections through endoscopic intervention, CT-navigated drainage, or reoperation and drain insertion.

\section{VACStent ${ }^{\circledR}$}

The esophageal VACStent ${ }^{\circledR}$ (Möller Medical GmbH, Germany) (Fig. 1a) consists of a delivery system loaded with a fully covered SEMS which is mounted on an inner catheter and constrained by an outer tube (Fig. 1b-d). The delivery system has a length of $1,000 \mathrm{~mm}$ and a diameter of $14 \mathrm{~mm}(42 \mathrm{~F})$. The SEMS is made of nitinol wire and fully covered with a silicone-parylene layer to prevent tissue ingrowth. The outside of the stent body is covered by an open-pore polyurethane foam, which is connected to a drainage tube (length of 2,000 $\mathrm{mm}$ and diameter of $10 \mathrm{~F}$ ) inside the inner catheter. The SEMS is released distally by retracting the outer tube. When it is completely expanded, the VACStent ${ }^{\circledR}$ has a dumbbell shape with an inner body diameter of $14 \mathrm{~mm}$, which increases to $30 \mathrm{~mm}$ at both flare ends to prevent stent migration. The VACStent ${ }^{\circledR}$ is only available in one size (length of $720 \mathrm{~mm}$ and diameter of $14 \mathrm{~mm}$ ), and it is CE (Conformitée Européenne) certified.

\section{Stent Treatment}

The procedures from which we gathered the data presented in this study were performed by 2 experienced interventional endoscopists (i.e., S.-H.C., U.T.) either under sedation with propofol (e.g., Fresenius Kabi Germany $\mathrm{GmbH}$ ) or under general anesthesia, depending on the general condition of the patient. For endoscopic guidance throughout the stent placement, a flexible video esophagogastroduodenoscope (e.g., GIF-H190 and GIF-XP180N; Olympus Medical Systems, Tokyo, Japan) was used. After assessing the size of the leak, we determined the stent position according to the following criteria: (1) sufficient coverage of the leak by the polyurethane foam and (2) a distance of $1 \mathrm{~cm}$ from both stent ends to the leak.

After advancing the delivery system to the leak over the guide wire, the VACStent ${ }^{\circledR}$ was carefully deployed under endoscopic guidance, and sufficient expansion of it was verified. Afterward, the drainage tube was moved from the oral to the nasal cavity and connected to an electric vacuum pump (e.g., VivanoTec ${ }^{\circledR}$ Hartmann AG, Germany) with a continuous suction of $125 \mathrm{~mm} \mathrm{Hg}$ (Fig. 2). The VACStent ${ }^{\circledR}$ was exchanged after 2-4 days. Two hours before the extraction started, the electric vacuum pump was turned off. Just before the endoscopic extraction, $20 \mathrm{~mL}$ of sterile water (e.g., Ampuwa ${ }^{\circledR}$; Fresenius Kabi Germany $\mathrm{GmbH}$ ) was injected via the drainage tube to wet the sponge and thus facilitate removal. After successful retrieval of the VACStent ${ }^{\circledR}$ using a standard rat tooth forceps, the leak was screened for any remaining pathology.

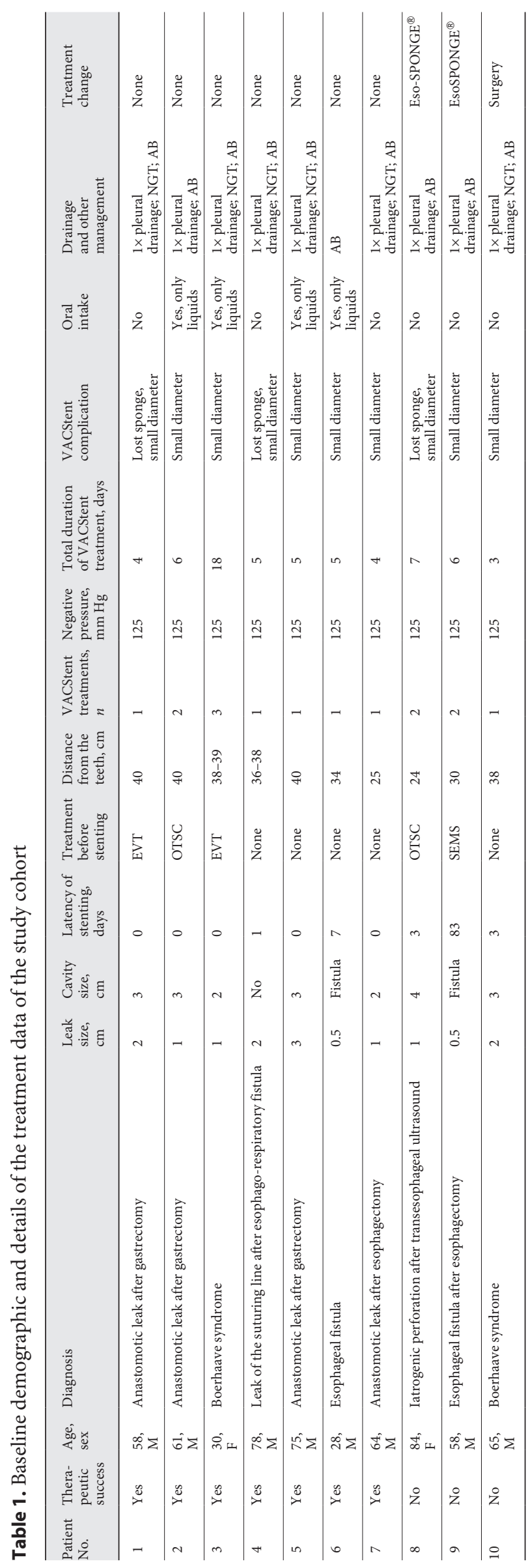




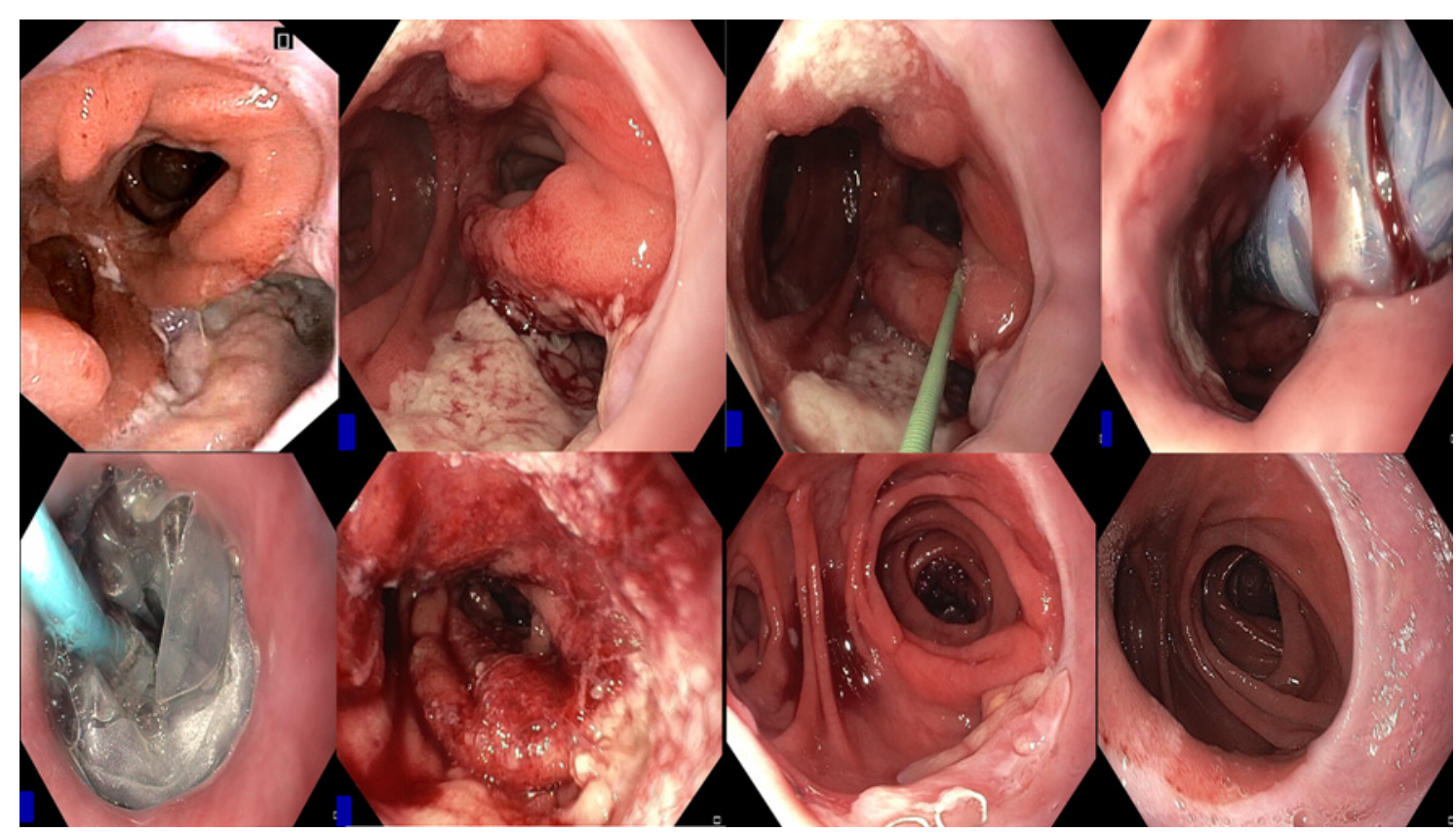

Fig. 3. The VACStent ${ }^{\circledR}$ treatment is shown in patient No. 1. a Endoscopy showing a large abscess cavity before sponge treatment. b After 1 session with tailored EVT. c Placement of the guidewire for the VACStent ${ }^{\circledR}$. d-e Implantation of the VACStent ${ }^{\circledR}$. $\mathbf{f}$ Sealed anastomotic leak with vital granulation. $\mathbf{g}$ Follow-up endoscopy after 1 month. $\mathbf{h}$ Follow-up endoscopy after 6 months.

\section{Results}

A total of 10 consecutive patients underwent VACStent ${ }^{\circledR}$ treatment for esophageal leaks at our hospital between May and September of 2019 (Table 1). Endoscopic images of 2 patients are shown in Figures 3 and 4.

The causes of the esophageal leaks were: iatrogenic perforation after transesophageal echocardiography $(n=$ $1)$, Boerhaave syndrome $(n=2)$, esophageal fistula $(n=$ 2 ), and anastomotic leak after upper gastrointestinal surgery $(n=5)$. Successful application of the VACStent ${ }^{\circledR}$ was achieved in all of the interventions ( $n=15 ; 100 \%)$.

Although we achieved technical success in $100 \%$ of the cases, we faced some technical issues throughout: After VACStent ${ }^{\circledR}$ placement, the inner diameter of the stent body did not expand to the full diameter of $14 \mathrm{~mm}$ in any of these patients. This was resolved by pneumatic balloon dilations (e.g., CRE ${ }^{\mathrm{TM}}$ Balloon Dilatation Catheter; Boston Scientific, Marlborough, MA, USA), which we administered specifically to ensure the possibility of oral intake.

The sponge was lost in the esophagus during the extraction procedure in 3 patients (No. 1, 4, and 8) because the sponge had grown into the tissue. In addition, the first-generation VACStent ${ }^{\circledR}$ lacked fixation of the sponge at the stent body. The sponges had to be removed separately directly after the stent extraction. We mobilized the sponge in the esophagus and pushed it into the stomach, from where we evacuated it with a standard endoscopic snare. After treatment of 5 patients, we received the newgeneration VACStent ${ }^{\circledR}$ and this problem did not occur again.

Clinical success without the need for further interventions or surgery was achieved in 7 out of 10 patients (70\%). Five out of 10 patients (50\%) had undergone previous endoscopic therapy using SEMS, EVT, or an overthe-scope-clip (OTSC). The VACStent ${ }^{\circledR}$ was used as firstline treatment in 5 patients (success rate: $80 \% ; 4 / 5$ ) and as second-line treatment in 5 patients (success rate: $60 \%$; $3 / 5$ ). The median overall duration of this treatment was 5 days (range: 3-18). No stent-related complications during the treatment (e.g., migration or leak persistence) occurred. No severe VACStent ${ }^{\circledR}$ treatment-related adverse events occurred. After VACStent ${ }^{\circledR}$ treatment no patient developed a stenosis of the anastomosis or needed further endoscopic management.

VACStent ${ }^{\circledR}$ treatment was not successful in 3 patients. Patient No. 9 was diagnosed with a complex enteropleural fistula at the esophageal-gastric anastomosis after oncological Ivor Lewis esophagectomy. VACStent ${ }^{\circledR}$ treatment failed to permanently close the fistula, and several interventional procedures, including a tailored EVT (e.g., Eso-SPONGE ${ }^{\circledR}$ Aesculap AG, Germany), were necessary for complete fistula closure. VACStent ${ }^{\circledR}$ treatment also failed to achieve closure of an iatrogenic esophageal perforation in patient No. 8. Since the sponge of the VACStent ${ }^{\circledR}$ and an additional CT-guided external drainage could not sufficiently clean the pleural cavity, we switched 


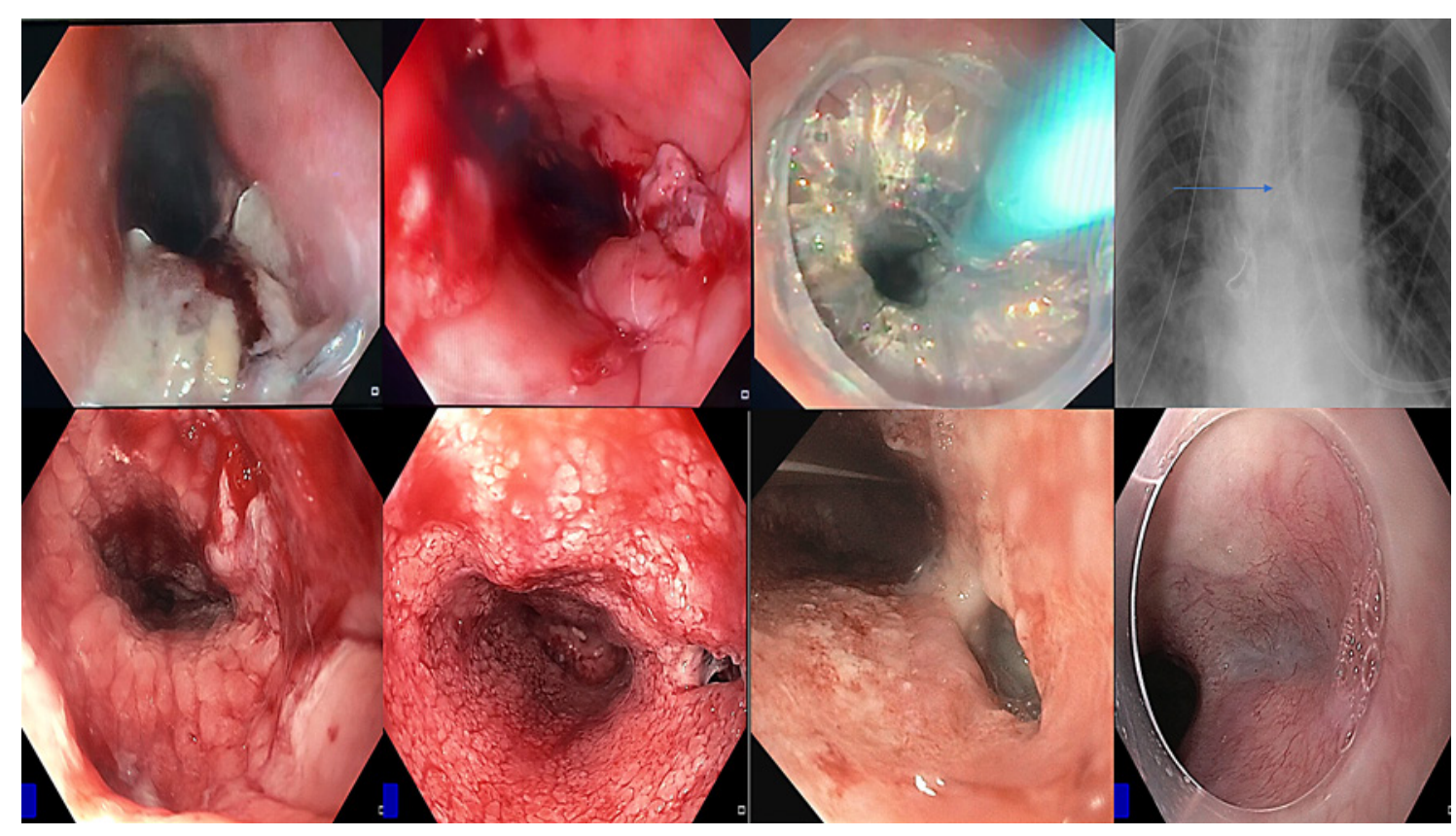

Fig. 4. The VACStent ${ }^{\circledR}$ treatment is shown in patient No. 8. a Endoscopy showing an insufficient closure with OTSC. $\mathbf{b}$ Esophageal perforation after OTSC removal. $\mathbf{c}$ Placement of the VACStent ${ }^{\circledR}$. $\mathbf{d}$ X-ray showing the position of the VACStent ${ }^{\circledR}$ (arrow). e Area of the flare end after VACStent ${ }^{\circledR}$ removal. $f$ VACStent ${ }^{\circledR}$ removal: vital granulation tissue but no healing progression. $\mathbf{g}$ Treatment change to EVT (Eso-SPONGE ${ }^{\circledR}$ ). $\mathbf{h}$ Complete closure of the leak after completed tailored EVT treatment.

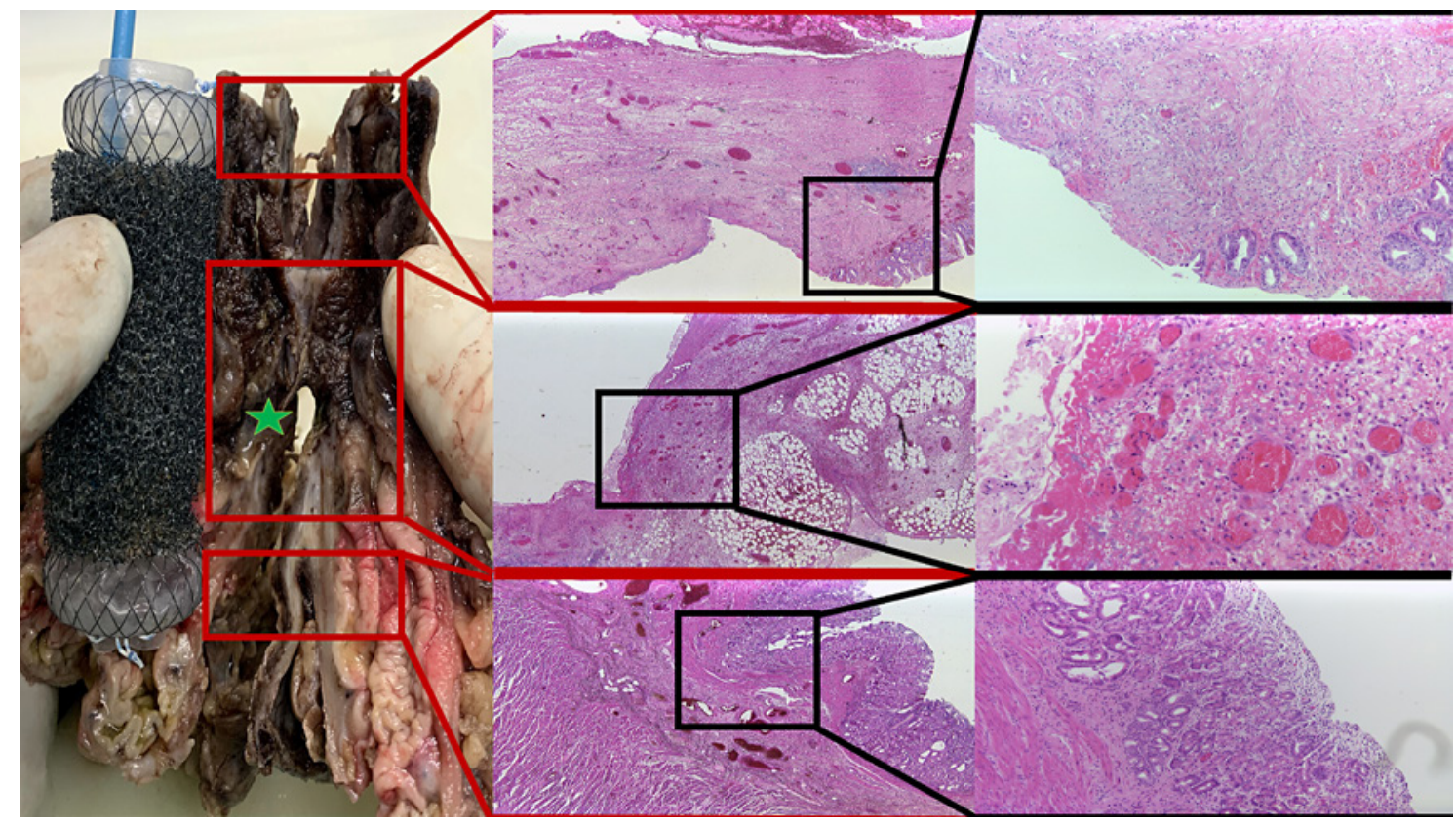

Fig. 5. Histopathological specimen of patient No. 10. a Position of the VACStent ${ }^{\circledR}$ at the esophagogastric junction (star: esophageal perforation). b, c Esophageal mucosa around the upper flare end of the VACStent ${ }^{\circledR}$ : focal mucosal erosion and ulceration down to the submucosa. Submucosal edema. Partial overcoating by high columnar epithelium with reactive nuclear alterations, as a high extension of Barrett epithelium. d, e Location of the perforation: transmural ulceration (i.e., perforation) into the adjacent fatty tis- sue. At the base of the ulceration granulation tissue is demarcated, consisting of fibroblasts and in-growth of capillaries. Neutrophilic granulocytes dominate the inflamed tissue reaction on the side of plasma cells and lymphocytes. f, $\mathbf{g}$ Gastric mucosa around the lower flare end of the VACStent ${ }^{\circledR}$ : histomorphologically unremarkable gastric cardiac mucosa. Hematoxylin and eosin $(\mathbf{b}-\mathbf{g}) . \times 2.5$ $(\mathbf{b}, \mathbf{d}, \mathbf{f})$ and $\times 10(\mathbf{c}, \mathbf{e}, \mathbf{g})$. 
to EVT using a tailored Eso-SPONGE ${ }^{\circledR}$ which we placed in the wound cavity in patient No. 8. Patient No. 10 was referred to our hospital with Boerhaave syndrome. The patient became increasingly clinically unstable with a septic shock so that an esophagectomy was necessary. In the histological examination of the esophagus of patient No. 10 , we detected granulation tissue around the perforation with direct sponge contact, although the VACStent ${ }^{\circledR}$ treatment was not successful (Fig. 5). Further, in the area of direct contact between the upper flare end of the stent and the esophageal tissue, no esophageal damage subjacent to the submucosa was found. Additionally, the cardiac gastric mucosa was unaffected even in the area of the lower flare end of the VACStent ${ }^{\circledR}$.

\section{Discussion}

Esophageal perforations and postoperative esophageal leaks are considered life-threatening conditions with a high morbidity and mortality $[1,2]$.

Endoscopic treatment options include the well-established therapy with SEMS as well as EVT, a promising alternative [3-7]. An innovative therapeutic approach in this context is the use of an esophageal hybrid SEMS $\left(\right.$ VACStent $^{\circledR}$ ) for leak management [12]. This SEMS combines the technology of the 2 established methods (SEMS and EVT) in a single medical device.

A major advantage of using VACStent ${ }^{\circledR}$ treatment is the possibility of maintaining the esophageal passage for oral intake while simultaneously sealing and draining the leak through EVT. In fact, 4 of our patients (No. 2, 3, 5, and 6) were able to drink liquids for the duration of the treatment.

In our experience, the possibility to focus the suction force toward the leak and surrounding tissue results in faster and more efficient granulation (Fig. 3f, 4f) [13]. Our data showed a shorter treatment duration (median 5 days) compared to studies with a mono treatment with EVT, which may imply that this treatment combination has a positive effect on the healing process $[7,14,15]$.

Serious adverse events of using SEMS are migration and perforation. Migration of self-expanding esophageal stents occurs in up to $36 \%$ of cases [5, 16-18]. In our study, the radial expansion force of the SEMS in combination with the suction force of EVT was able to keep the VACStent ${ }^{\circledR}$ in position in all of the patients, especially those with different diameters of the intestinal lumen (e.g., esophagogastrostomy). Perforations of the gastrointestinal tract due to SEMS can be caused by incorrectly selected diameters and the radial expansion force [19]. The VACStent ${ }^{\circledR}$ develops contrary traction forces in the esophagus, i.e., a push effect caused by the radial expansion force of the SEMS and a pull effect caused by the suc- tion force of EVT. These opposing forces arise especially in the transition zone between the flare ends and the suction area of the stent shaft so that the risk of perforation can increase. In our study, no serious adverse event in terms of esophageal damage occurred. While the histopathological examination of the esophagus of patient No. 10 showed focal mucosal erosion and ulceration down to the submucosa with submucosal edema in the area of the flare ends, no damage subjacent to the submucosa was found (Fig. 5). These results seem to suggest that the combination of a SEMS and vacuum therapy is safe to use, especially in this critical zone. Nevertheless, the pathological examination of a larger patient cohort is needed to verify our results.

The VACStent ${ }^{\circledR}$ treatment has a few limitations. Firstly, it cannot be used in close proximity to the upper esophageal sphincter, as smaller dimensions are not available and the application in a proximal position is associated with significant discomfort for the patient. Another limitation of VACStent ${ }^{\circledR}$ treatment are leaks with big wound cavities. While EVT can be applied inside a cavity by using an individualized sponge to achieve efficient and complete drainage, the sponge of the VACStent ${ }^{\circledR}$ remains intraluminal and may have a lower impact on the contaminated tissue inside the cavity as a result of the missing direct contact.

From an economic perspective, the costs of EVT are twice as high compared to those of SEMS treatment due to the higher rate of necessary endoscopies [20]. The costs of VACStent ${ }^{\circledR}$ treatment are estimated to be even higher since they were exchanged in the same interval as EVT in our study. On the other hand, efficacy concerning leakage closure may be higher and the optimal exchange interval has yet to be determined.

Since the VACStent ${ }^{\circledR}$ is a new and unestablished treatment option, close patient monitoring is essential, and exit strategies such as salvage surgery need to be considered continuously.

Our results show that VACStent ${ }^{\circledR}$ treatment for leaks in the esophagus represents a safe and technically feasible option. The number of patients in this study was not enough to show clear advantages of the new technique. Nevertheless, our study demonstrates that the VACStent ${ }^{\circledR}$ is a new, promising, and safe alternative to EVT and SEMS for selected patients. Larger studies are needed to identify criteria to improve patient selection and to support the significant advantages of VACStent ${ }^{\circledR}$ treatment.

\section{Acknowledgment}

We would like to thank all the nurses at our interdisciplinary endoscopy unit for their excellent assistance. We thank Dr. phil. Lisa-Marie Teubler for proofreading.
Chon/Töx/Lorenz/Rieck/Wagner/ Kleinert/Fuchs/Goeser/Quaas/Bruns 


\section{Statement of Ethics}

This study was conducted ethically in accordance with the World Medical Association Declaration of Helsinki and with the approval of the Ethics Committee of the University of Cologne, Germany (No. 20-1152). Written informed written was obtained from each of the participants included in this study.

\section{Conflict of Interest Statement}

The authors have no conflict of interests to declare.

\section{Funding Sources}

None.

\section{Author Contributions}

Seung-Hun Chon: study conception and design; data acquisition, analysis, and interpretation; drafting and final approval of this paper. Ulrich Toex: study conception and design; data acquisition, analysis, and interpretation; and revision and final approval of this paper. Florian Lorenz and Isabel Rieck: data acquisition and interpretation, and revision and final approval of this paper. Britta Janina Wagner: data analysis and interpretation, and revision and final approval of this paper. Robert Kleinert: data interpretation, and revision and final approval of this paper. Hans Friedrich Fuchs: data acquisition, and revision and final approval of this paper. Tobias Goeser and Alexander Quaas: study design, and revision and final approval of this paper. Christiane Josephine Bruns: study conception and design; data acquisition, analysis, and interpretation; and drafting and final approval of this paper.

\section{References}

1 Brinster CJ, Singhal S, Lee L, Marshall MB, Kaiser LR, Kucharczuk JC. Evolving options in the management of esophageal perforation. Ann Thorac Surg. 2004 Apr;77(4):1475-83.

2 Rutegård M, Lagergren P, Rouvelas I, Lagergren J. Intrathoracic anastomotic leakage and mortality after esophageal cancer resection: a population-based study. Ann Surg Oncol. 2012 Jan;19(1):99-103.

3 Kähler G. Anastomotic Leakage after Upper Gastrointestinal Surgery: endoscopic Treatment. Visc Med. 2017 Jun;33(3):202-6.

4 Paspatis GA, Dumonceau JM, Barthet M, Meisner S, Repici A, Saunders BP, et al. Diagnosis and management of iatrogenic endoscopic perforations: European Society of Gastrointestinal Endoscopy (ESGE) Position Statement. Endoscopy. 2014 Aug;46(8):693711.

5 Dasari BV, Neely D, Kennedy A, Spence G, Rice P, Mackle E, et al. The role of esophageal stents in the management of esophageal anastomotic leaks and benign esophageal perforations. Ann Surg. 2014 May;259(5):852-60.

6 Plum PS, Herbold T, Berlth F, Christ H, Alakus H, Bludau M, et al. Outcome of Self-Expanding Metal Stents in the Treatment of Anastomotic Leaks After Ivor Lewis Esophagectomy. World J Surg. 2019 Mar;43(3):8629.

7 Bludau M, Fuchs HF, Herbold T, Maus MK, Alakus H, Popp F, et al. Results of endoscopic vacuum-assisted closure device for treatment of upper GI leaks. Surg Endosc. 2018 Apr; 32(4):1906-14.
8 Berlth F, Bludau M, Plum PS, Herbold T, Christ H, Alakus H, et al. Self-Expanding Metal Stents Versus Endoscopic Vacuum Therapy in Anastomotic Leak Treatment After Oncologic Gastroesophageal Surgery. J Gastrointest Surg. 2019 Jan;23(1):67-75.

9 Scognamiglio P, Reeh M, Karstens K, et al. Endoscopic vacuum therapy versus stenting for postoperative esophago-enteric anastomotic leakage: systematic review and metaanalysis. Endoscopy. 2020 Aug;52(8):632-42.

10 Valli PV, Mertens JC, Kröger A, Gubler C, Gutschow C, Schneider PM, et al. Stent-oversponge (SOS): a novel technique complementing endosponge therapy for foregut leaks and perforations. Endoscopy. 2018 Feb; 50(2):148-53.

11 Bartella I, Mallmann C, Bürger M, Toex U, Goeser T, Bruns C, et al. Stent-over-sponge (SOS): a rescue option in patients with complex postoperative anastomotic leaks after esophagectomy. Endoscopy. 2019 Aug; 51(8):E227-8.

12 Chon SH, Bartella I, Bürger M, et al. VACStent: a new option for endoscopic vacuum therapy in patients with esophageal anastomotic leaks after upper gastrointestinal surgery. Endoscopy. 2020 May;52(5):E166-7.

13 Glass GE, Murphy GF, Esmaeili A, Lai LM, Nanchahal J. Systematic review of molecular mechanism of action of negative-pressure wound therapy. Br J Surg. 2014 Dec;101(13): 1627-36.

14 Kuehn F, Schiffmann L, Janisch F, Schwandner F, Alsfasser G, Gock M, et al. Surgical Endoscopic Vacuum Therapy for Defects of the Upper Gastrointestinal Tract. J Gastrointest Surg. 2016 Feb;20(2):237-43.
15 Laukoetter MG, Mennigen R, Neumann PA, Dhayat S, Horst G, Palmes D, et al. Successful closure of defects in the upper gastrointestinal tract by endoscopic vacuum therapy (EVT): a prospective cohort study. Surg Endosc. 2017 Jun;31(6):2687-96.

16 Vleggaar FP, Siersema PD. Expandable stents for malignant esophageal disease. Gastrointest Endosc Clin N Am. 2011 Jul;21(3):37788.

17 Ott C, Ratiu N, Endlicher E, Rath HC, Gelbmann CM, Schölmerich J, et al. Self-expanding Polyflex plastic stents in esophageal disease: various indications, complications, and outcomes. Surg Endosc. 2007 Jun;21(6):88996.

18 van Boeckel PG, Dua KS, Weusten BL, Schmits RJ, Surapaneni N, Timmer R, et al. Fully covered self-expandable metal stents (SEMS), partially covered SEMS and self-expandable plastic stents for the treatment of benign esophageal ruptures and anastomotic leaks. BMC Gastroenterol. 2012 Feb;12(1):19. Epub ahead of print.

19 Baron TH. Expandable metal stents for the treatment of cancerous obstruction of the gastrointestinal tract. N Engl J Med. 2001 May; 344(22):1681-7.

20 Baltin C, Kron F, Urbanski A, Zander T, Kron A, Berlth F, et al. The economic burden of endoscopic treatment for anastomotic leaks following oncological Ivor Lewis esophagectomy. PLoS One. 2019 Aug;14(8):e0221406. 